\title{
Impact of Autophagy Inhibition at Different Stages on Cytotoxic Effect of Autophagy Inducer in Glioblastoma Cells
}

\author{
Chenguang Lia,b Yaohua Liu ${ }^{a, b} \quad$ Huailei Liua ${ }^{a, b}$ Weiguang Zhang ${ }^{a, b}$ Chen Shen ${ }^{a, b}$ \\ KenKa Cho ${ }^{c}$ Xin Chen ${ }^{a, b}$ Fei Penga,b Yunke Bi ${ }^{a, b}$ Xu Hou ${ }^{a, b}$ Zhuowen Yang ${ }^{d}$ \\ Zhixing Zhenga,b Kaikai Wang ${ }^{a, b}$ Xiaoxiong Wang ${ }^{a, b}$ Jiakang Zhanga,b \\ Chen Zhong ${ }^{a, b}$ Huichao Zou ${ }^{e}$ Xinjian Zhang ${ }^{a, b}$ Shiguang Zhao \\ aDepartment of Neurosurgery, The First Affiliated Hospital of Harbin Medical University, Harbin, \\ bInstitute of Brain Science, Harbin Medical University, Harbin, The People's Republic of China; \\ 'Department of Acupuncture, Takarazuka University of Medical and Health Care, Takarazuka City, \\ Japan; dDepartment of Endocrinology, The First Affiliated Hospital of Harbin Medical University, Harbin, \\ eDepartment of Pain Medicine, The Third Affiliated Hospital of Harbin Medical University, Harbin, The \\ People's Republic of China
}

\section{Key Word}

Apoptosis • Autophagic vacuole • Autophagy inducer • Autophagy inhibition • Glioblastoma multiforme

\begin{abstract}
Background/Aims: Glioblastoma multiforme (GBM) is the most malignant primary brain tumor with a poor prognosis. Combination treatment of autophagy inducer and autophagy inhibitor may be a feasible solution to improve the therapeutic effects. However, the correlation between them is unclear. The purpose of this study was to investigate the effect of autophagy inhibition at different stages on cytotoxicity of autophagy inducers in glioblastoma cells. Methods: Autophagy inhibition at early stage was achieved by 3-methyladenine (3-MA) or Beclin 1 shRNA. Autophagy inhibition at late stage was achieved by chloroquine (CQ) or Rab7 shRNA. Cell viability was assessed by MTT assay. Autophagy was measured using transmission electron microscopy and western blot. Apoptosis was measured using western blot and flowcytometry. Results: Inhibition of early steps of autophagy by 3-MA or Beclin 1 knockdown decreased the toxic effect of arsenic trioxide (ATO) in GBM cell lines. In contrast, blockade of autophagy flux at late stage by CQ or Rab7 knockdown enhanced the cytotoxicity of ATO, and caused accumulation of degradative autophagic vacuoles and robust apoptosis. Moreover, depletion of Beclin 1 abolished the synergistic effect of ATO and CQ by reducing autophagy and apoptosis. Combination of $\mathrm{CQ}$ with other autophagy inducers also induced synergistic apoptotic cell death. Conclusion: These results suggest that inhibition of late process of autophagy, not initial step, increases the cytotoxic effect of autophagy inducers via autophagy and apoptosis, which may contribute to GBM chemotherapy.

C. Li, Y. Liu and H. Liu contributed equally to this work.




\section{Cellular Physiology and Biochemistry}

Cell Physiol Biochem 2015;35:1303-1316

\begin{tabular}{l|l}
\hline DOI: $10.1159 / 000373952$ & (c) 2015 S. Karger AG, Basel
\end{tabular}

\begin{tabular}{l|l} 
Published online: February 11, 2015 & www.karger.com/cpb
\end{tabular}

Li et al.: Autophagy Inducer and Autophagy Inhibition

\section{Introduction}

Glioblastoma multiforme (GBM) is the most common and aggressive primary brain tumor in adults [1,2]. Despite of therapeutic advances, the median survival of GBM patients is only about 15 months after diagnosis $[3,4]$. The most critical hallmark of most cancers is resistance to apoptosis, which can be converted by autophagy, another type of programmed cell death $[5,6]$.

Autophagy is a lysosomal degradation process, which is associated with either cell survival or death [7]. Autophagy may allow tumors to survive under metabolic stress and lead to chemoresistance [8]. For this reason, autophagy inhibition can improve effect of chemotherapy as an adjuvant therapy for cancers [9]. However, significantly elevated levels of autophagy may result in cell death [10]. Several autophagy inducers exhibit anti-cancer function through persistent autophagy, such as the molecular target of rapamycin (mTOR) inhibitor rapamycin, phosphoinositide 3-kinase (PI3K) inhibitor LY294002, and arsenic trioxide (ATO) [11-18].

Interestingly, autophagy inhibitor and autophagy inducer, two kinds of contradictory drugs, sometimes produce synergistic effect on cancer therapy when used in combination $[19,20]$. By far, numbers of basic studies and clinical trials evaluating such effect in cancer treatment are in progress [11,19-26]. However, the published results were in conflict. For instance, autophagy inhibitor 3-methyladenine (3-MA) was found to decrease the toxicity of autophagy inducer temozolomide in GBM cells, while autophagy inhibitor bafilomycin A1 potentiate temozolomide cytotoxicity and induce apoptosis [21]. Since autophagy, as a multi-step process, can be inhibited at different stages, we hypothesized that inhibition of autophagy at different stages might play different roles in cytotoxic effect of autophagy inducers.

To test this hypothesis, in this study, we inhibited autophagy at different stages by pharmacological inhibitor or genetic ablation in GBM cells. To the best of our knowledge, the necessity of distinguishing between early and late stages of autophagy inhibition thus far has not been elucidated in GBM therapy. Our results indicated that inhibition of autophagy at late stage, not initial stage, increased the cytotoxic effect of autophagy inducers, providing a new approach for therapy of GBM.

\section{Materials and Methods}

\section{Cell line and reagents}

Human glioblastoma cell lines (U87 and U251) were obtained from RIKEN Cell Bank (Tsukuba Science City, Japan). Both cell lines were cultured in Dulbecco's Modified Eagle's Medium (DMEM) (Invitrogen, USA) with $10 \%$ fetal bovine serum (FBS, Invitrogen), $1 \%$ Streptomycin and penicillin at $37{ }^{\circ} \mathrm{C}$ in $5 \% \mathrm{CO}_{2}$. All experiments were performed in U87 and U251 cells between passage 10 and 20. ATO (Cat\#: 11311), Chloroquine (CQ, Cat\#: C6628), 3-MA (Cat\#: M9281), rapamycin (Cat\#: R117) , LY294002 (Cat\#: L9908), pepstatin A (Cat\#: P5318) were all purchased from Sigma (St. Louis, MO, USA). E-64d (Cas\#: 88321-09-9, Cayman, Canada) and pepstatin A were used to inhibit lysosome-mediated proteolysis.

MTT assay

GBM cells were seeded on 96-well plates at a density of $5 \times 10^{4} / \mathrm{ml}$. Cells were treated as indicated for the different experiments. Then $10 \mu \mathrm{l}$ MTT dye ( $5 \mathrm{mg} / \mathrm{ml}$, Cat\#: M2128, Sigma, USA) was added to each well at harvest time, and the plates were incubated at $37^{\circ} \mathrm{C}$ for $4 \mathrm{~h}$. Next the supernatants were replaced by 150 $\mu$ dimethyl sulfoxide (Cat\#: D2650, Sigma, USA) to stop the reaction. Optical density was measured on a spectrophotometric (Tecan, Switzerland) at a wavelength of $490 \mathrm{~nm}$.

Plasmids and Transfection

Plasmids of Beclin 1 shRNA (pGPU6/GFP/Neo-shBeclin 1, sense, 5'-CAGTTTGGCACAATCAATA-3'), Rab7 shRNA (pGPU6/GFP/Neo-shRab7, sense, 5'-GGCTAGTCACAATGCAGATAT-3') and the scrambled 


\section{Cellular Physiology and Biochemistry}

Cell Physiol Biochem 2015;35:1303-1316

\begin{tabular}{l|l}
\hline DOI: $10.1159 / 000373952$ & (C) 2015 S. Karger AG, Basel
\end{tabular}

www.karger.com/cpb

Li et al.: Autophagy Inducer and Autophagy Inhibition

control vector (pGPU6/GFP/Neo-shNC, sense, 5'-GTTCTCCGAACGTGTCACGT-3') were purchased from GenePharma company (Shanghai, China). GBM cells were transiently transfected with Lipofectamine 2000 (Invitrogen, USA) for 48h according to Manufacturer's instructions.

\section{Western blot analysis}

Total protein were extracted from cultured cells. The cells were lysed in RIPA buffer with protease inhibitor. The lysates were separated by 10-15\% SDS-PAGE gels, and then transferred to PVDF membranes (Millipore, Bedford, MA, USA). The membranes were blocked in 5\% skim milk with tween for $1 \mathrm{~h}$ and incubated with primary antibodies overnight at $4{ }^{\circ} \mathrm{C}$, followed by incubation with fluorescence-conjugated secondary antibodies (1:5000, Invitrogen, USA). Immunoreactive complexes were visualized using BeyoECL Plus (Beyotime, China). To perform western blot analysis, the following antibodies were used: rabbit LC3B antibody (1:1000; Sigma, USA), rabbit Beclin 1 antibody (1:500; Santa Cruz, CA, USA), rabbit SQSTM1 antibody (1:1000; Santa Cruz, CA, USA), rabbit caspase-3 antibody (1:1000; Cell Signaling Technology, USA), rabbit Rab7a antibody (1:250, Sigma, USA), mouse $\beta$-actin antibody (1:2000; Santa Cruz, CA, USA).

Transmission electron microscopy

U87 and U251 cells were cultured in $60 \mathrm{~mm}$ dishes for $24 \mathrm{~h}$ to adhere. After treatment, cells were fixed with $2.5 \%$ glutaraldehyde in phosphate buffer and preserved at $4^{\circ} \mathrm{C}$ for further processing. Subsequently, cells were post-fixed with $1 \%$ osmium tetroxide followed by an increasing gradient dehydration step using ethanol and acetone. Cells were then embedded in araldite, and ultrathin section were obtained (50-60 $\mathrm{nm}$ ), placed on uncoated copper grids, and stained with $3 \%$ lead citrate-uranyl acetate. The sections were examined with a transmission electron microscope (TEM; Hitachi, H-7650, Tokyo, Japan).

Cell apoptosis assay by flow cytometry

For assessment of apoptosis, Annexin V-FITC assay was used to measure apoptotic cells by flow cytometry according to the manufacturer's instructions (Invitrogen, USA). Briefly, cells $\left(2 \times 10^{5}\right.$ per well) were cultured in six-well plates to $70 \%-80 \%$ confluence. After treatment cells were collected by trypsinization, washed with ice-cold phosphate-buffered saline (PBS) twice and resuspended in Annexin V-labeling solution with FITC conjugated anti-Annexin V. After 15 min incubation at room temperature, cells were centrifuged and resuspended with propidium iodide (PI). Analysis was carried out by flow cytometry (BD FACS, USA). Results were expressed as the percentage of apoptotic cells at early stage (PI negative and Annexin $\mathrm{V}$ positive) and at late stage (PI positive and Annexin $\mathrm{V}$ positive).

\section{Statistical analysis}

The data from triplicate experiments were expressed as the mean \pm SD. Statistical analysis between groups was performed using two-tailed Student's $t$ test (GraphPad Prism version 5.0), where $P<0.05$ was considered statistically significant (indicated by single asterisk in the Figures), $P<0.01$ was strongly significant (indicated by double asterisks), and $P<0.001$ was more strongly significant (indicated by triple asterisks).

\section{Results}

ATO reduced GBM cell viability and induced autophagy

To examine the cytotoxic effect of ATO on GBM cell lines, we treated two GBM cell lines (U87 and U251) with ATO at concentrations ranging from $1 \mu \mathrm{M}$ to $10 \mu \mathrm{M}$ for $24 \mathrm{~h}$ and 48 h. As shown in Fig. 1A, ATO inhibited cell viability in both cell lines in a dose-dependent manners. Cells incubated with ATO for $48 \mathrm{~h}$ were reduced more significantly than $24 \mathrm{~h}$. Then we investigated whether ATO can trigger autophagy by examining autophagic vacuoles (AVs) and by measuring level of LC3-II (autophagy marker) and SQSTM1 (a specific autophagy substrate). Beclin 1, a key regulator of entry into autophagy, was also examined to assess autophagy. After exposing GBM cells to $3 \mu \mathrm{M}$ ATO for $12 \mathrm{~h}$, the ultrastructure was analyzed by TEM. As shown in Fig. 1B, numerous vesicles with double membranes characteristic of autophagosome were observed in ATO group, while untreated cells showed few vesicles. 
Fig. 1. Effect of ATO treatment on GBM cell viability and autophagy. (A) Cell viability of U87 and U251 cells was determined by the MTT assay after exposure to different concentrations of ATO for $24 \mathrm{~h}$ and $48 \mathrm{~h}$. The data were normalized with control. Values represent Mean \pm SD of three independent experiments. ${ }^{*} P<.05$; ${ }^{* *} P$ $<.01$; ${ }^{* * *} P<.001$ compared with controls. (B) TEM photomicrographs of U87 and U251 cells. U87 and U251 cells were treated with cell culture media (negative control) or ATO $(3 \mu \mathrm{M})$ for $12 \mathrm{~h}$. High magnification photomicrographs were displayed. Arrows indicate autophagic vacuoles (AVs). N, nucleus; $\mathrm{M}$, mitochondrion; E, endoplasm reticulum. Scale bars represent $2 \mu \mathrm{m}$. (C) Total cell lysates of U87 and U251 cells were extracted after incubation with indicated concentrations $(\mu \mathrm{M})$ of ATO for 12 hours. Cell lysates were blotted with anti-LC3, anti-Beclin 1 and anti-SQSTM1 antibodies; anti- $\beta$-actin antibody was used as loading control. (D) Total cell lysates of U87 and U251 cells were extracted after incubation with $3 \mu \mathrm{M}$ ATO for $0 \mathrm{~h}, 4 \mathrm{~h}$, or $12 \mathrm{~h}$ in the presence or absence of E-64d $(10 \mu \mathrm{g} / \mathrm{ml})$ and pepstatin A $(10 \mu \mathrm{g} / \mathrm{ml})$. Cell lysates were blotted with anti-LC3; anti- $\beta$-actin protein antibody was used as loading control.

Furthermore, western blot analysis using LC3 and SQSTM1 antibodies revealed that ATO induced autophagy in a dose-dependent manner. However, Beclin 1 level in the same lysates was not influenced (Fig. 1C). This is consistent with a previous finding that the Beclin 1 initiates autophagy via its interaction with class III PI3K, other than elevating its protein level [7]. Cysteine protease inhibitor E-64d and aspartic protease inhibitor pepstatin A can inhibit lysosome-mediated proteolysis and be used to measure autophagy flux [27]. We observed that ATO increased LC3-II level in a time-dependent manner. Note that the amount of LC3-II became higher in the presence of inhibitors, suggesting that autophagy flux was occurring (Fig. 1D). Together, these data indicated that ATO decreased GBM cell viability, accompanied with the activation of autophagy.

3-MA inhibited autophagy induced by ATO and reversed the cytotoxic effect of ATO in GBM

To determine whether the cell death was induced by autophagy, 3-MA was used to inhibit autophagy. 3-MA can block an early stage of autophagy by inhibiting the class III PI3K $[20,27,28]$. As shown in Fig. 2A , 1 mM 3-MA was able to reduce cell viability in both GBM cell lines significantly. However, the combination of $10 \mu \mathrm{M}$ ATO with $1 \mathrm{mM} 3-\mathrm{MA}$ exhibited 
A
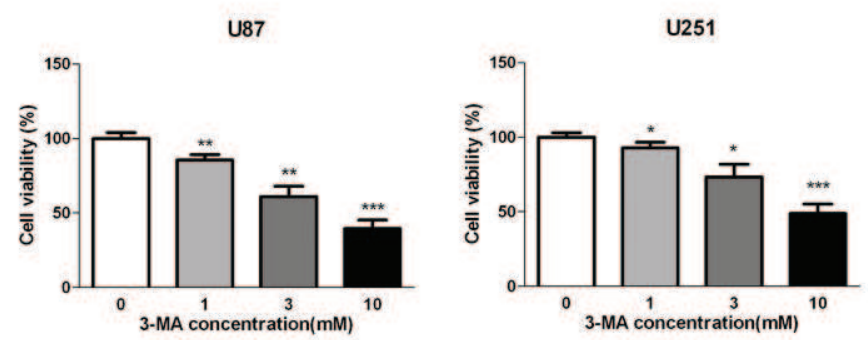

B

U87

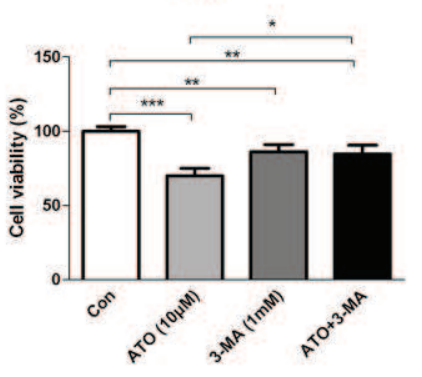

U251

C
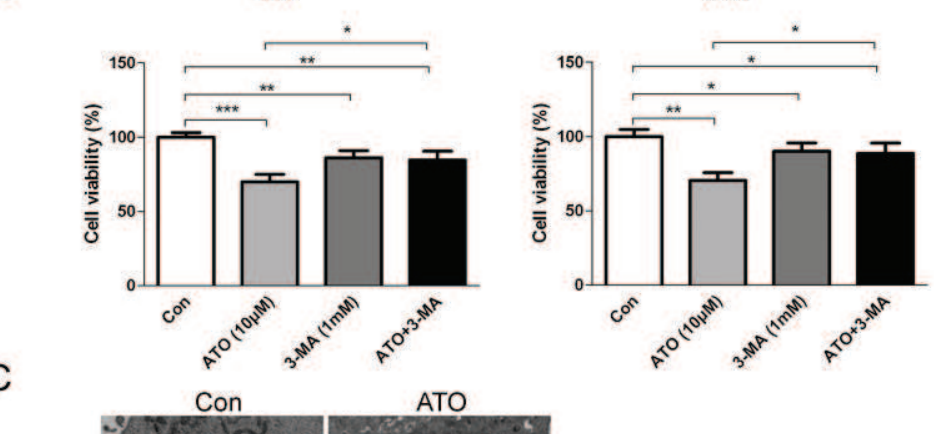

ATO

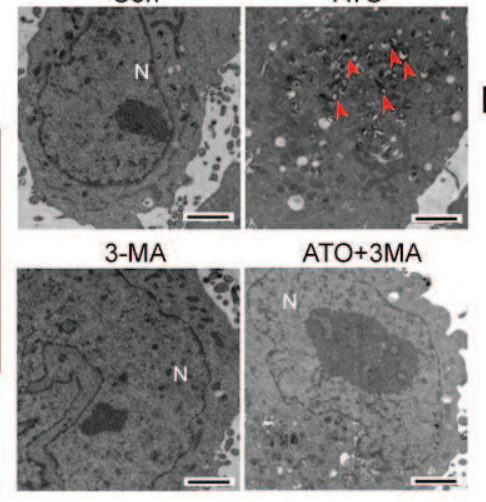

D

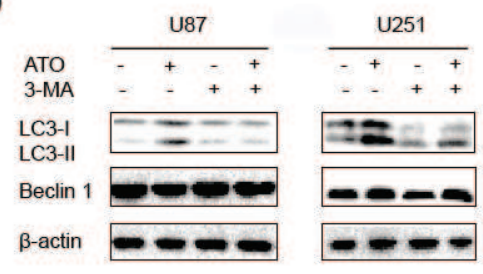

Fig. 2. Effect of ATO and 3-MA in GBM cell lines. (A) Cell viability of U87 and U251 cells incubated with different concentrations of 3-MA for $24 \mathrm{~h}$ was measured by MTT assay. (B) U87 and U251 cells were treated with ATO $(10 \mu \mathrm{M})$, with or without 3-MA $(1 \mathrm{mM})$ for $24 \mathrm{~h}$. The cell viability was then evaluated by MTT assay. Values represent Mean $\pm \mathrm{SD}$ of three independent experiments. ${ }^{*} P<.05 ;{ }^{* *} P<.01 ;{ }^{* * *} P<.001$. (C) TEM photomicrographs of U87 cells treated with $10 \mu \mathrm{M}$ ATO and $1 \mathrm{mM} 3$-MA alone, or in combination for $12 \mathrm{~h}$. Arrows indicate AVs. N, nucleus. Scale bars represent $2 \mu \mathrm{m}$. (D) Total cell lysates were extracted from U87 and U251 cells treated as above. Then cell lysates were blotted with anti-Beclin 1 and anti-LC3 antibodies; anti- $\beta$-actin antibody was used as loading control.

little cytotoxic effect (Fig. 2B). Results of TEM and western blots also indicated that 3-MA inhibited the autophagy level induced by ATO, as both number of AVs and level of LC3-II decreased (Fig. 2C and D). Together, these data demonstrated that 3-MA inhibited autophagy and cytotoxicity induced by ATO, suggesting that ATO inhibits cell growth via autophagy.

CQ impaired the clearance of autophagic vacuoles and sensitized GBM cells to ATO treatment

To further investigate the role autophagy played in cell death caused by ATO, another autophagy inhibitor CQ was studied in GBM cell lines. CQ can arrest the latter step of autophagy, fusion and degradation of autolysosome [29]. The results of MTT assay showed that GBM cells were sensitive to single treatment with CQ, but not with $5 \mu \mathrm{M}$ CQ (Fig. 3A). However, combination of $3 \mu \mathrm{M}$ ATO and $5 \mu \mathrm{M}$ CQ produced dramatically higher inhibition rates compared with single-agent treatment (Fig.3B). Unlike 3-MA, combination treatment 


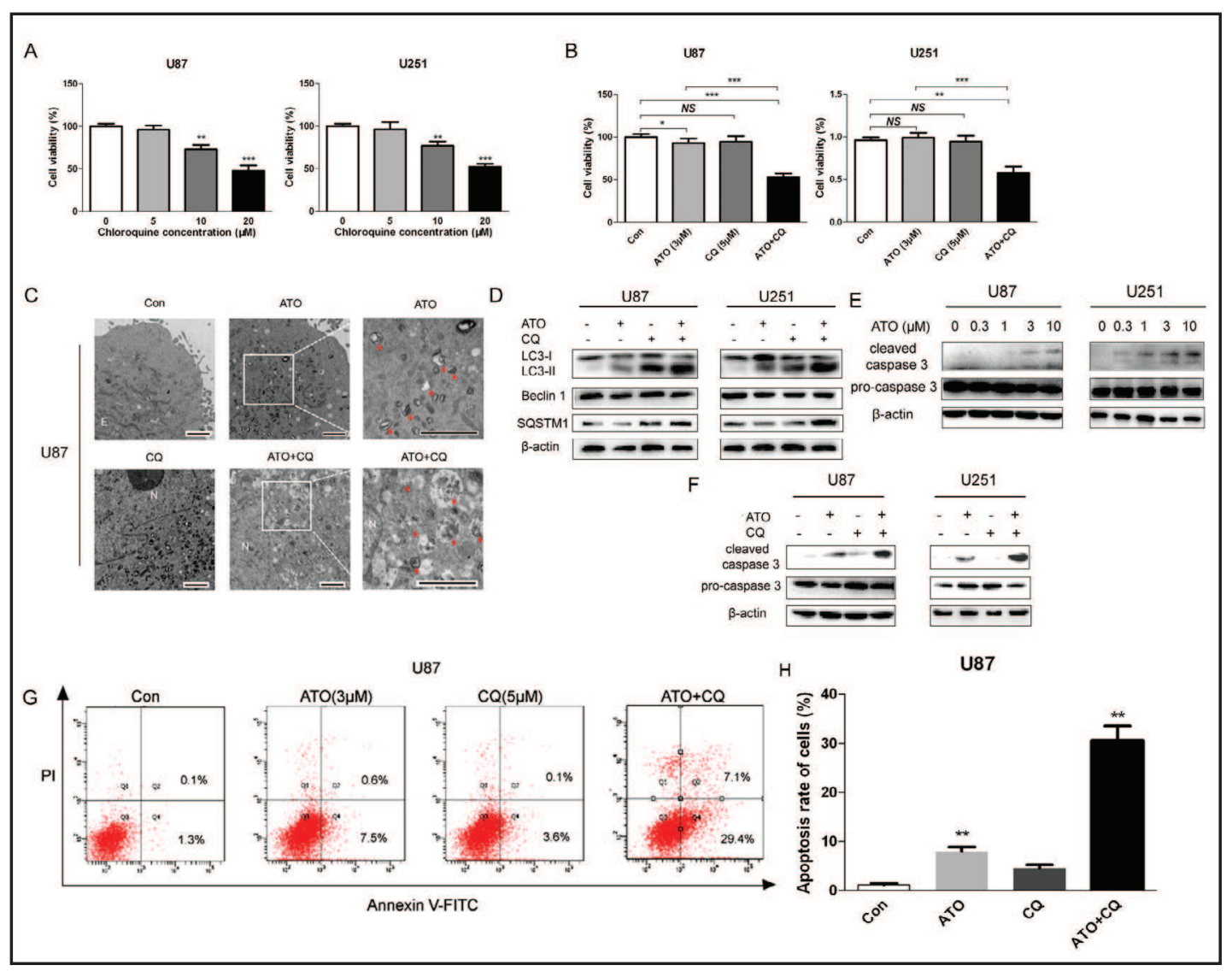

Fig. 3. Effect of ATO and CQ in GBM cell lines. (A) Cell viability of U87 and U251 incubated with different concentrations of CQ for $24 \mathrm{~h}$ was measured by MTT assay. (B) U87 and U251 cells were treated with ATO $(3 \mu \mathrm{M})$, with or without CQ $(5 \mu \mathrm{M})$ for $24 \mathrm{~h}$. The cell viability was then evaluated by MTT assay. Values represent Mean \pm SD of three independent experiments. NS, not significant; ${ }^{*} P<.05 ;{ }^{* *} P<.01 ;{ }^{* * *} P<.001$. (C) TEM photomicrographs of U87 cells treated with $3 \mu \mathrm{M}$ ATO and $5 \mu \mathrm{M}$ CQ alone, or in combination for $12 \mathrm{~h}$. Arrows indicate AVs. N, nucleus. Scale bars represent $2 \mu \mathrm{m}$. (D) Effect of ATO and CQ on Beclin 1 and LC3 protein expression in GBM cells. Total cell lysates were extracted from U87 and U251 cells treated as above and blotted with anti-Beclin 1, anti-LC3 and anti-SQSTM1 antibodies; anti- $\beta$-actin antibody was used as loading control. (E) Effect of ATO on caspase 3 protein level in U87 and U251 cells. Cell lysates were extracted from cells treated with ATO at the indicated concentration for $24 \mathrm{~h}$, then cell lysates were blotted with anti-caspase 3 antibodies; anti- $\beta$-actin antibody was used as loading control. (F) Effect of combination of ATO and CQ on caspase 3 protein level in U87 and U251 cells. Total cell lysates were extracted from cells treated as described in Fig.3B. Cell lysates were blotted with anti-caspase 3 antibodies; anti- $\beta$-actin antibody was used as loading control. (G) Cell death of U87 cells treated as above was assessed by flow cytometry. The data are shown as percentages of apoptotic cells at early stage (PI negative and Annexin V positive) and at late stage (PI positive and Annexin V positive). (H) Statistical analysis of apoptosis rate induced by ATO in presence or absence of $\mathrm{CQ}$, which was detected in $(\mathrm{G}) .{ }^{* *} P<.01$.

of ATO with CQ led to accumulation of AVs and increased level of LC3-II (Fig. 3C and D). In addition, SQSTM1 level was higher in ATO+CQ group compared with control, suggesting that autophagy flux was blocked by CQ at late stage. We next sought to characterize whether the cell death was associated with apoptosis. Caspase 3 cleavage is a central hallmark of apoptosis. After treated with indicated concentration of ATO, the level of cleaved caspase 3 increased in a dose-dependent manner (Fig. 3E). Moreover, ATO + CQ combination resulted in higher level of cleaved caspase 3 compared either treatment alone, indicating that the combination of ATO and CQ induced stronger apoptosis (Fig. 3F). The result of flow cytometry was also consistent with this finding (Fig. 3G and H). Together, these data suggested that CQ 


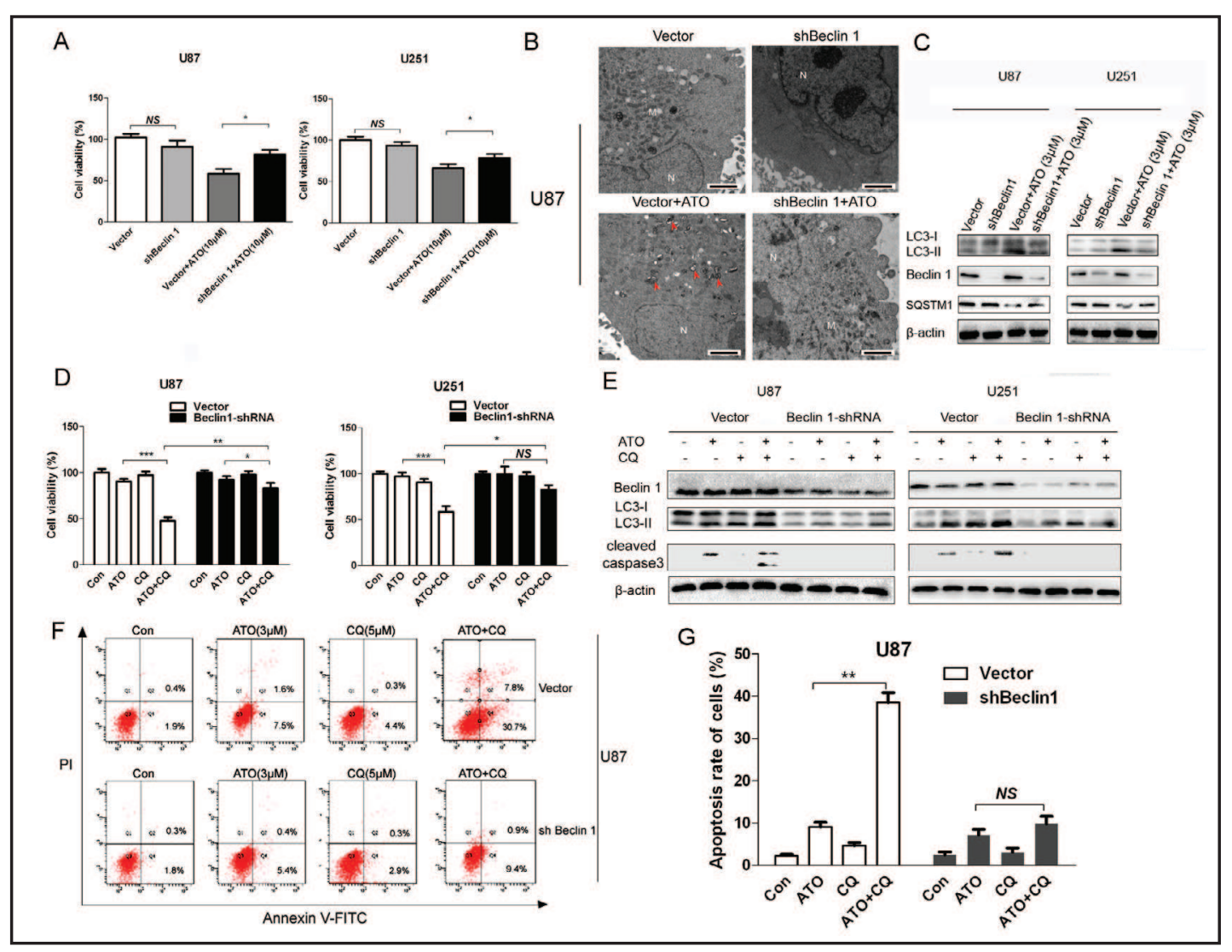

Fig. 4. Effect of Beclin 1 knockdown on combination treatment of ATO and CQ. (A) Effects of Beclin 1 knockdown on the cytotoxicity of ATO in GBM cells. U87 and U251 cells were transiently transfected with scrambled shRNA or Beclin 1 shRNA. After a $48 \mathrm{~h}$ transfection cells were left untreated or treated with ATO $(3 \mu \mathrm{M})$ for $24 \mathrm{~h}$. Cell viability was then measured by MTT assay. Data are expressed as Mean \pm SD of three independent experiments. NS, not significant; ${ }^{*} P<.05$. (B) U87 cells were transiently transfected with scrambled shRNA or Beclin 1 shRNA, and after $48 \mathrm{~h}$ cells were left untreated or treated with ATO $(3 \mu \mathrm{M})$ for $12 \mathrm{~h}$. TEM photomicrographs of U87 cells show AVs (arrows). N, nucleus; M, mitochondrion. Scale bars represent 2 $\mu \mathrm{m}$. (C) Effects of Beclin 1 knockdown on Beclin 1 and LC3 protein level expression in GBM cells treated with ATO. Cells were treated as above. Cell lysates were blotted with anti-Beclin 1 and anti-LC3 antibodies; anti- $\beta$-actin antibody was used as loading control. (D) U87 and U251 cells were transfected with Beclin 1 shRNA and scrambled shRNA for $48 \mathrm{~h}$. Then cells were incubated with ATO (3 $\mu \mathrm{M})$, with or without CQ (5 $\mu \mathrm{M})$ for $24 \mathrm{~h}$. The cell viability was then evaluated by MTT assay. Data are expressed as Mean \pm SD of three independent experiments. NS, not significant; ${ }^{*} P<.05$; ${ }^{* *} P<.01 ;{ }^{* * *} P<.001$. (E) Total cell lysates were extracted from U87 and U251 cells treated as above. Cell lysates were blotted with anti-Beclin 1, anti-LC3, and anti-caspase 3 antibodies; anti- $\beta$-actin antibody was used as loading control. (F) Effect of Beclin 1 depletion on U87 cells apoptosis. U87 cells were treated as above. Flow cytometry was performed to analyze cell apoptosis. The data are shown as percentages of apoptotic cells at early stage and at late stage. (G) Statistical analysis of apoptosis rate induced by ATO in presence or absence of CQ which was detected in (F). NS, not significant; ${ }^{* *} P<.01$.

sensitized GBM cells to ATO treatment, impaired clearance of degradative AVs, and induced caspase 3-dependent apoptosis.

Autophagy inhibition by Beclin 1 knockdown abolished synergistic effect of ATO and CQ

As most chemical inhibitors of autophagy are not specific [27], we used Beclin 1 shRNA to determine the role of autophagy induced by ATO. Similar to 3-MA, Beclin 1 knockdown also decreased the cytotoxic effect of $10 \mu \mathrm{M}$ ATO (Fig. 4A). In addition, the results of TEM and western blots showed that Beclin 1 suppression decreased autophagy level in GBM 
Fig. 5. Effect of Rab7 knockdown on cytotoxicity of ATO. (A) U87 and U251 cells were transiently transfected with scrambled shRNA or Rab7 shRNA. After a $48 \mathrm{~h}$ transfection cells were left untreated or treated with ATO $(3 \mu \mathrm{M})$ for $24 \mathrm{~h}$. Cell viability was then measured by MTT assay. Values represent Mean \pm SD of three independent experiments. NS, not significant; ${ }^{*} P<.05$; ${ }^{* *} P<$ $.01 ;{ }^{* * *} P<.001$. (B) U87 cells were transiently transfected with scrambled shRNA or Rab7 shRNA, and after $48 \mathrm{~h}$ cells were left untreated or treated with ATO (3 $\mu \mathrm{M}$ ) for $12 \mathrm{~h}$. TEM photomicrographs of U87 cells show AVs (arrows). N, nucleus. Scale bars represent $2 \mu \mathrm{m}$. (C) Total cell lysates were extracted from U87 and U251 cells treated as de-
A

U87

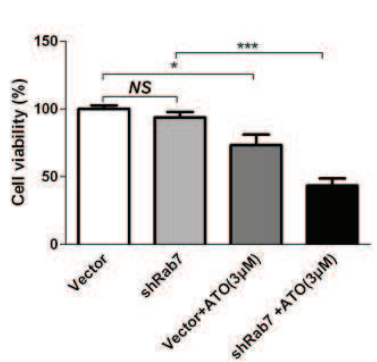

B

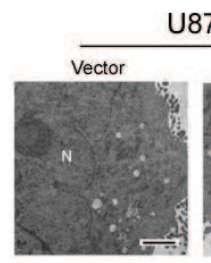

Vector+ATO

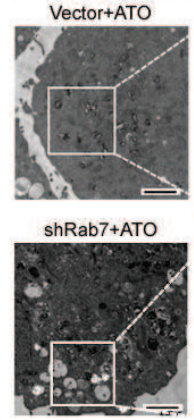

87

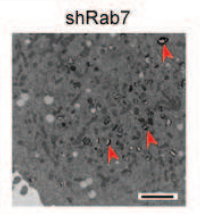

D

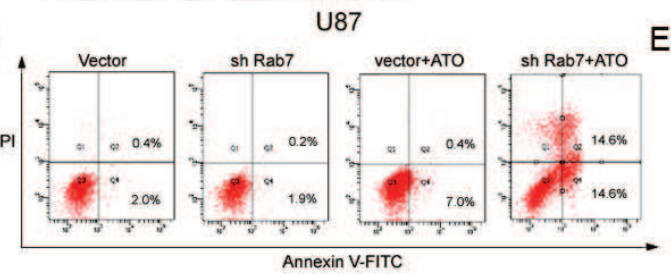

C

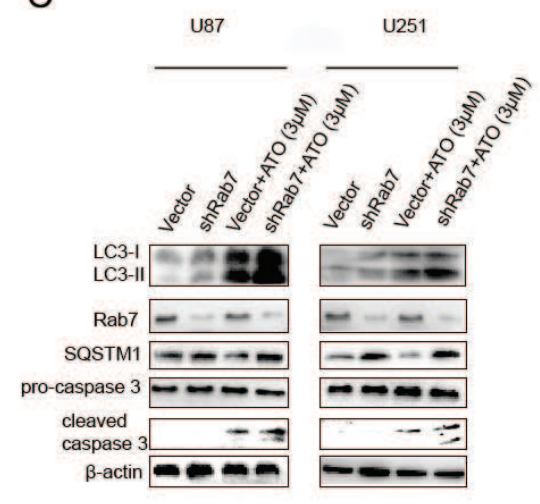

U251

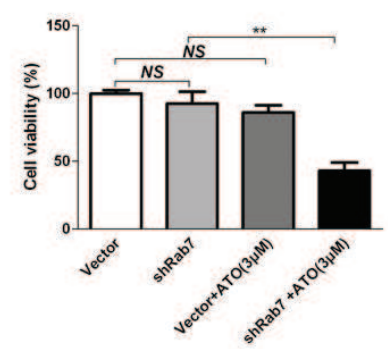

U87

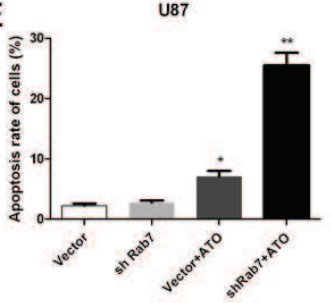

scribed in Fig.5A. Cell lysates were blotted with anti-Rab7, anti-LC3, anti-SQSTM1 and anti-caspase 3 antibodies; anti- $\beta$-actin antibody was used as loading control. (D) Effect of Rab7 depletion on U87 cells apoptosis. U87 cells were treated as above. Flow cytometry was performed to analyze apoptosis. The data are shown as percentages of apoptotic cells at early stage and at late stage. (E) Statistical analysis of apoptosis rate induced by ATO in presence or absence of CQ, which was detected in (D). NS, not significant; ${ }^{*} P<.05$; ${ }^{* *} P<.01$.

cell lines treated with ATO (Fig. 4B and C). These data indicate that blockade of autophagy at initial stage decreases cytotoxicity of ATO. Notably, Beclin 1 knockdown prevented the synergistic cell death induced by ATO + CQ combination, suggesting that Beclin 1 is required for the synergistic effect of combination treatment (Fig. 4D). The level of LC3-II and cleaved caspase 3 in all groups with Beclin 1 knockdown decreased significantly compared with the scrambled shRNA groups, suggesting that both autophagy and apoptosis induced by ATO and CQ were dependent on Beclin 1 (Fig. 4E). The results of flow cytometry also demonstrated that Beclin 1 depletion could decrease apoptosis induced by ATO + CQ combination (Fig. 4F and G). Collectively, these data demonstrated that the synergistic effect of ATO and CQ was mediated by autophagy and apoptosis in a Beclin 1-dependent manner. 


\section{Cellular Physiology $\quad$ Cell Physiol Biochem 2015;35:1303-1316

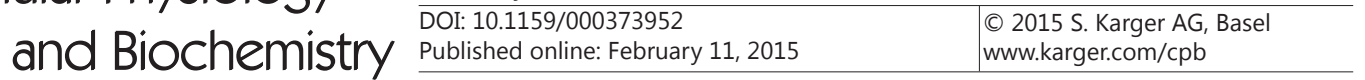

Fig. 6. CQ sensitized GBM cells to other autophagy inducers rapamycin and LY294002. (A) U87 and U251 cells were treated with CQ (5 $\mu \mathrm{M})$, or 3-MA (1 $\mathrm{mM})$, or rapamycin (30 nM), or rapamycin + CQ combination, or rapamycin + 3-MA combination, or LY294002 (15 $\mu \mathrm{M})$, or LY294002 + CQ combination, or LY294002 + 3-MA combination for 24 h. Then cell viability was measured by MTT assay. NS, not significant; ${ }^{*} P<.05$; ${ }^{* *} P<.01$ (B) U87 cells were treated with rapamycin (30 nM), or LY294002 (15 $\mu \mathrm{M})$, or CQ (5 $\mu \mathrm{M})$, or rapamycin + CQ combination, or LY294002 + CQ combination for 12 h. TEM photomicrographs of U87 cells show AVs (arrows). N, nucleus. Scale bars represent 2 $\mu \mathrm{m}$. (C) U87 cells were treated with $30 \mathrm{nM}$ rapamycin or $15 \mu \mathrm{M}$ LY294002 for $6 \mathrm{~h}$ or $24 \mathrm{~h}$ in the presence or absence of $5 \mu \mathrm{M}$ CQ. Cell lysates were blotted with anti-LC3 and anti-SQSTM1 antibo-

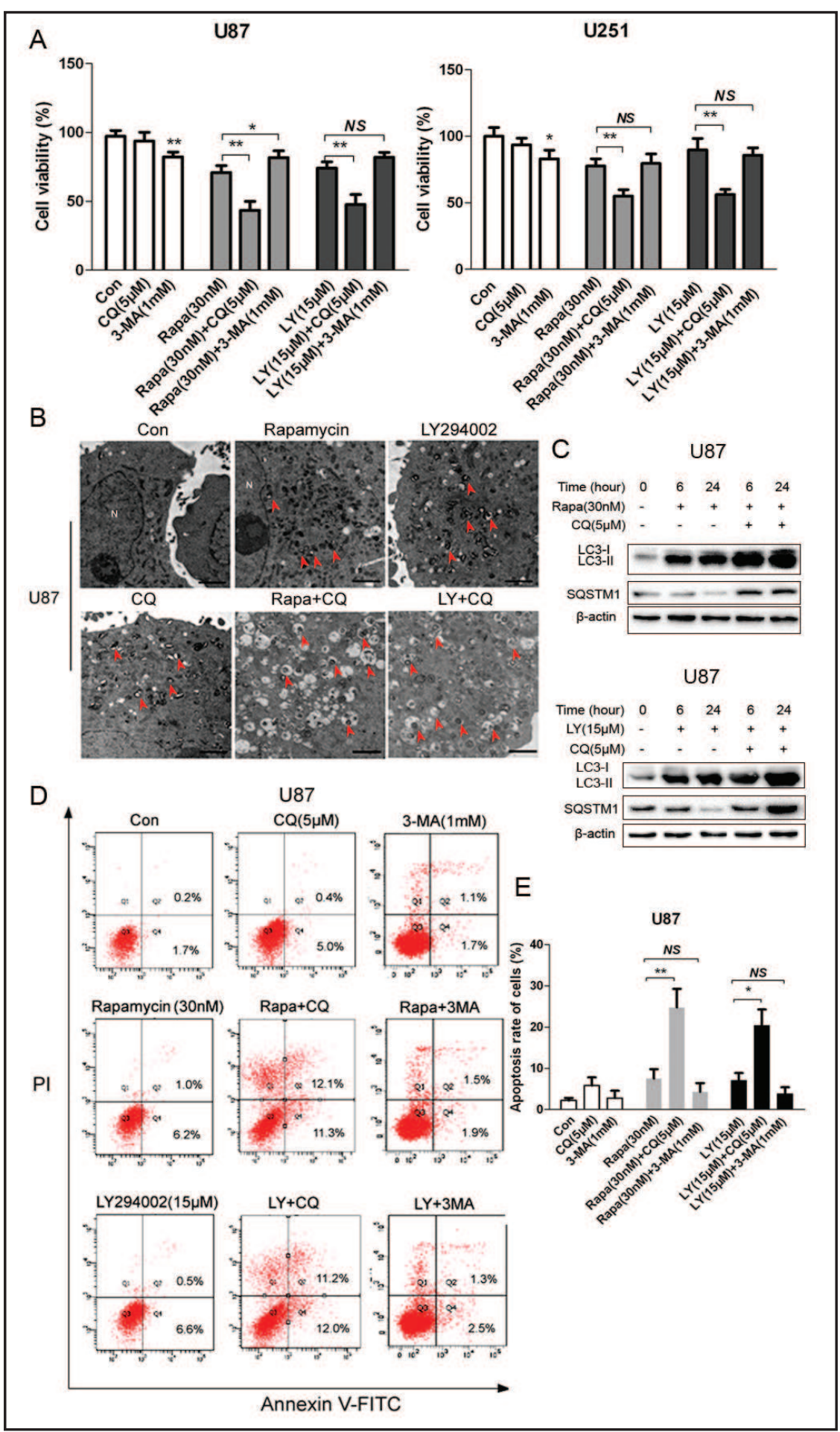

dies; anti- $\beta$-actin antibody was used as loading control. (D) U87 cells were treated as described in Fig.6A. Flow cytometry was performed to analyze apoptosis. The data are shown as percentages of apoptotic cells at early stage and at late stage. (E) Statistical analysis of apoptosis rate induced by ATO in presence or absence of CQ, which was detected in (D). NS, not significant; ${ }^{*} P<.05 ;{ }^{* *} P<.01$.

\section{Autophagy inhibition by Rab7 knockdown enhanced cytotoxic effect of ATO}

Since CQ inhibits autophagy at late stage, we hypothesized that autophagy blockade at late stage might enhance the cytotoxic effect of ATO. To test this, we knocked down the

\section{KARGER}




\section{Cellular Physiology and Biochemistry}

Cell Physiol Biochem 2015;35:1303-1316

\begin{tabular}{l|l}
\hline DOI: $10.1159 / 000373952$ & (C) 2015 S. Karger AG, Basel
\end{tabular}

\begin{tabular}{l|l} 
Published online: February 11, 2015 & www.karger.com/cpb \\
\hline
\end{tabular}

Li et al.: Autophagy Inducer and Autophagy Inhibition
Fig. 7. A schematic model that illustrates how 3-MA or CQ affect the autophagy flux induced by autophagy inducer in GBM.

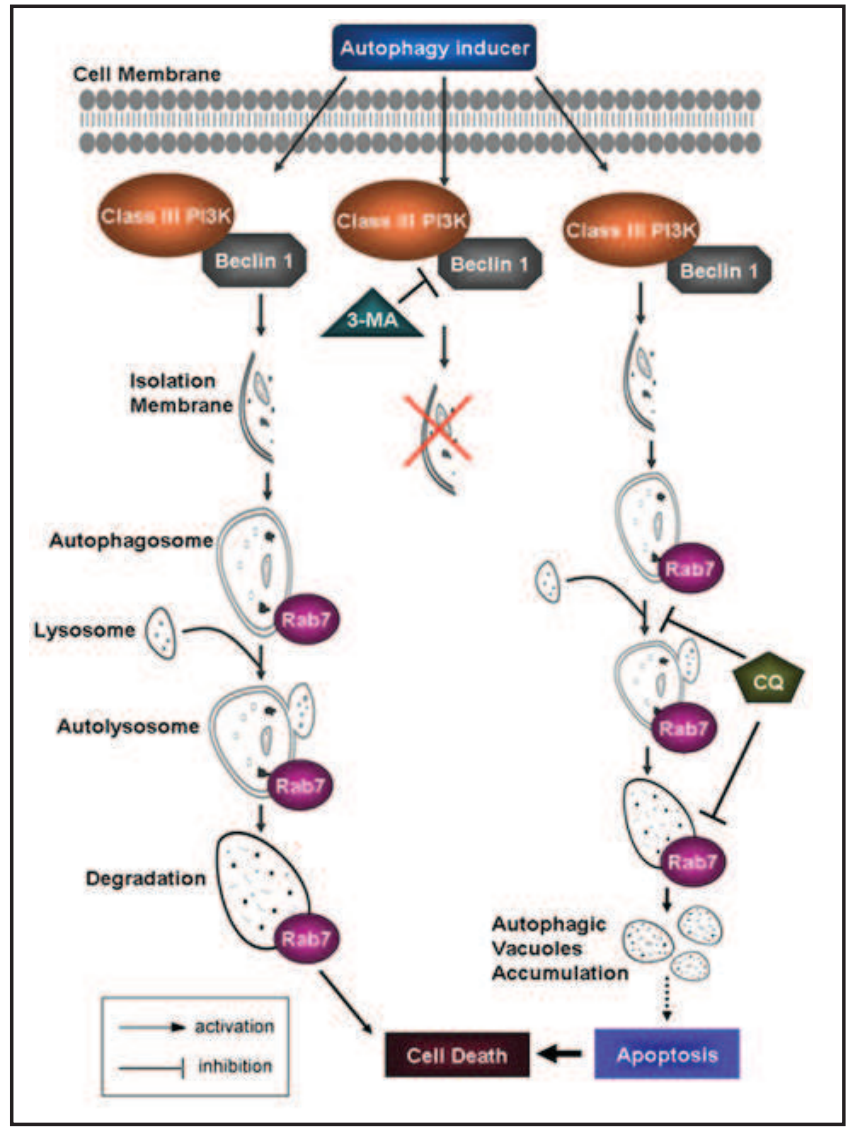

expression of a key autophagy regulator Rab7a (termed Rab7) using shRNA. Rab7 is one of small Rab GTPase required by fusion of autophagosome and lysomsomes [7, 30-32]. Similar to CQ Rab7 knockdown enhanced the cytotoxic effect of $3 \mu \mathrm{M}$ ATO significantly (Fig. 5A). In addition, accumulation of AVs were observed in U87 cells co-treated with Rab7 depletion and ATO (Fig. 5B). LC3-II and SQSTM1 also increased in group with Rab7 shRNA, suggesting that autophagic flux was blocked by Rab7 depletion at late stage (Fig. 5C). Furthermore, the combination treatment of Rab7 shRNA and ATO led to increased level of cleaved caspase-3 level suggesting induction of apoptosis (Fig. 5C). Results of flow cytometry also indicated that, after combination treatment, U87 cells had a markedly higher apoptotic percentage compared with negative control group (Fig. 5D and E). Taken together, these data indicate that autophagy inhibition at late stage sensitizes GBM cells to ATO, and causes accumulation of AVs and synergistic apoptosis.

Inhibition autophagy in early or late stage had different effect on autophagy inducers

To evaluate whether cytotoxicity of other autophagy inducers can be enhanced by autophagy inhibition at late stage, rapamycin and LY294002 were used to induce autophagy. As shown in Fig. 6A, CQ sensitized GBM cells to rapamycin or LY294002 treatment significantly, whereas 3-MA decreased their cytotoxic effect. Although LY294002 is known to either block autophagy or active autophagy, previous study and our results revealed that LY294002 induced autophagy in GBM cell lines (Fig. 6B and C) [33]. TEM results also showed increased AVs in two groups with CQ and autophagy inducer combination (Fig. 6B). Western blot results showed that CQ could block autophagy flux induced by either rapamycin or LY294002 at late stage (Fig. 6C). In addition, the results of flow cytometry showed that combination of CQ with rapamycin or LY294002 significantly increase apoptosis (Fig. 6D and E). Taken together, these results indicate that combination with autophagy inducer and autophagy inhibition at late stage induces synergistic apoptotic cell death. 


\section{Cellular Physiology and Biochemistry}

Cell Physiol Biochem 2015;35:1303-1316

\begin{tabular}{l|l}
\hline DOI: $10.1159 / 000373952$ & (C) 2015 S. Karger AG, Basel
\end{tabular}

\begin{tabular}{l|l} 
Published online: February 11, 2015 & www.karger.com/cpb
\end{tabular}

Li et al.: Autophagy Inducer and Autophagy Inhibition

\section{Discussion}

Autophagy is a highly dynamic process termed autophagy flux. As shown in Fig. 7, autophagy begins with the formation of isolation membrane, a process regulated by class III PI3K-Beclin 1 complex. Then the membrane elongates and subsequently encloses to form the autophagosome, a double membrane structure. Following autophagosome formation, its outer membrane fuses with lysosomes to form autolysosomes, a single membrane structure. This process requires a number of regulators, such as Rab7 [7]. Ultimately, the lysosomal hydrolases degrade the autophagosome contents [7]. In this study, we demonstrate that 3-MA or Beclin 1 knockdown inhibits the initial step of autophagy induced by autophagy inducer, leading to blockade of autophagy flux from the beginning. By contrast, CQ or Rab7 knockdown inhibits autophagosome-lysosome fusion and degradation steps, leading to accumulation of degradative AVs and enhanced apoptotic cell death. Given the auxiliary role of autophagy inhibitor may vary greatly at different stages, a distinction should be made between early stage and late stage of autophagy.

Our results indicated that the effect of autophagy inhibitor and autophagy inducer combination involved both autophagy and apoptosis. The relationship between autophagy and apoptosis in cancers is complex. Autophagy and apoptosis regulate each other mostly in an inhibitory manner $[12,20,34,35]$. However, sometimes autophagy may favour the induction of apoptosis. Apoptosis may begin with autophagy and autophagy can often end with apoptosis [36]. For instance, autophagosome formation generates a platform of activation of caspase 3 [37]. In addition, accumulation of autophagosomes may be toxic and trigger apoptosis, which is associated with increased ROS (reactive oxygen species) and subsequent mitochondrial permeabilization [38]. Thus, we speculated that autophagy inhibition and autophagy inducer combination induced apoptosis mostly through accumulation of AVs. This is supported by our findings that induction of robust apoptosis was always accompanied by accumulation of degradative AVs. Supporting this, a previous research showed that CQ-induced AV accumulation induced GBM cells to undergo apoptosis [39]. However, the underlying mechanism is still need to be further studied.

Our data have shown that Rab7 knockdown sensitized GBM cells to ATO treatment and induced stronger apoptosis. Thus far about 10 known Rab proteins are found to regulate autophagy, among which only Rab7 has a defined role in late stage of autophagy [40]. In addition, many Rab members, including Rab7, play important roles in invasiveness and metastasis in cancers [32, 41]. Furthermore, Rab7 was overexpressed in many cancers, including GBM, based on gene-centric robust multiarray analysis data [32]. These data support Rab7 as a promising target, especially when combined with autophagy inducers.

Our results demonstrated that CQ increased cytotoxicity of autophagy inducers in a Beclin-1 dependent manner, suggesting that autophagy plays a crucial role in such synergistic effects. However, Maycotte et al. reported that CQ sensitized autophagy inducers like rapamycin and LY294002 independent of autophagy [11]. We believe the reason for this inconsistency is that the molecule we targeted for inhibition of autophagy is Beclin 1, whereas their target is Atg12, a downstream of Beclin 1. Therefore, our method may inhibit autophagy more completely. In this study, we only used TEM and measurement of LC3-II and SQSTM1 protein level to detect autophagy flux rather than fluorescence microscopy with GFP-Cherry-LC3 construct, which was specially designed for monitoring autophagic flux. Although we could confirm the autophagy maturation/degradation blockade by the increase in LC3-II and SQSTM1 level, the best method to monitor autophagy flux is use of multiple assays [27].

In conclusion, our data indicated that inhibition of late steps of autophagy enhanced cytotoxicity of autophagy inducing drugs. Therefore, administration of such combination may act as a new approach to the treatment of GBM after further testing via in vivo experiments and clinical trials.

\section{KARGER}




\section{Cellular Physiology and Biochemistry}

Cell Physiol Biochem 2015;35:1303-1316

\begin{tabular}{l|l}
\hline DOI: $10.1159 / 000373952$ & (C) 2015 S. Karger AG, Basel
\end{tabular}

\begin{tabular}{ll} 
Published online: February 11, 2015 & www.karger.com/cpb \\
\hline
\end{tabular}

Li et al.: Autophagy Inducer and Autophagy Inhibition

\section{Abbreviation}

GBM (Glioblastoma multiforme); ATO (arsenic trioxide); CQ (chloroquine); 3-MA (3-methyladenine); PI3K (phosphoinositide 3-kinase); TEM (transmission electron microscopy); AV (autophagic vacuole).

\section{Acknowledgments}

This work was supported by the National Natural Science Foundation of China $(81472368$ to Shiguang Zhao, 81172388 and 81372701 to Yaohua Liu, and 81402061 to Huailei Liu), Heilongjiang overseas fund (NO.LC2011C21 to Yaohua Liu) and the First Affiliated Hospital of Harbin Medical University Foundation (2014B05 to Huailei Liu).

\section{Disclosure Statement}

The authors declare that there are no conflicts of interest.

\section{References}

1 Louis DN, Ohgaki H, Wiestler OD, Cavenee WK, Burger PC, Jouvet A, Scheithauer BW, Kleihues P: The 2007 WHO classification of tumours of the central nervous system. Acta Neuropathol 2007;114:97-109.

2 Chen Y, Chou WC, Ding YM, Wu YC: Caffeine inhibits migration in glioma cells through the ROCK-FAK pathway. Cell Physiol Biochem 2014;33:1888-1898.

3 Park JK, Hodges T, Arko L, Shen M, Dello Iacono D, McNabb A, Olsen Bailey N, Kreisl TN, Iwamoto FM, Sul J, Auh S, Park GE, Fine HA, Black PM: Scale to predict survival after surgery for recurrent glioblastoma multiforme. J Clin Oncol 2010;28:3838-3843.

4 Furnari FB, Fenton T, Bachoo RM, Mukasa A, Stommel JM, Stegh A, Hahn WC, Ligon KL, Louis DN, Brennan C, Chin L, DePinho RA, Cavenee WK: Malignant astrocytic glioma: genetics, biology, and paths to treatment. Genes Dev 2007;21:2683-2710.

5 Kaza N, Kohli L, Roth KA: Autophagy in brain tumors: a new target for therapeutic intervention. Brain Pathol 2012;22:89-98.

6 Mora R, Regnier-Vigouroux A: Autophagy-driven cell fate decision maker: activated microglia induce specific death of glioma cells by a blockade of basal autophagic flux and secondary apoptosis/necrosis. Autophagy 2009;5:419-421.

7 Tanida I: Autophagosome formation and molecular mechanism of autophagy. Antioxid Redox Signal 2011;14:2201-2214.

8 Wei Y, Zou Z, Becker N, Anderson M, Sumpter R, Xiao G, Kinch L, Koduru P, Christudass CS, Veltri RW, Grishin NV, Peyton M, Minna J, Bhagat G, Levine B: EGFR-mediated Beclin 1 phosphorylation in autophagy suppression, tumor progression, and tumor chemoresistance. Cell 2013;154:1269-1284.

9 Chen N, Debnath J: Autophagy and tumorigenesis. FEBS Lett 2010;584:1427-1435.

10 Shimizu S, Yoshida T, Tsujioka M, Arakawa S: Autophagic cell death and cancer. Int J Mol Sci 2014;15:31453153.

11 Maycotte P, Aryal S, Cummings CT, Thorburn J, Morgan MJ, Thorburn A: Chloroquine sensitizes breast cancer cells to chemotherapy independent of autophagy. Autophagy 2012;8:200-212.

12 Chiu HW, Ho YS, Wang YJ: Arsenic trioxide induces autophagy and apoptosis in human glioma cells in vitro and in vivo through downregulation of survivin. J Mol Med (Berl) 2011;89:927-941.

13 Carminati PO, Donaires FS, Marques MM, Donadi EA, Passos GA, Sakamoto-Hojo ET: Cisplatin associated with LY294002 increases cytotoxicity and induces changes in transcript profiles of glioblastoma cells. Mol Biol Rep 2014;41:165-177. 


\section{Cellular Physiology and Biochemistry}

Cell Physiol Biochem 2015;35:1303-1316

Li et al.: Autophagy Inducer and Autophagy Inhibition

14 Kanzawa T, Zhang L, Xiao L, Germano IM, Kondo Y, Kondo S: Arsenic trioxide induces autophagic cell death in malignant glioma cells by upregulation of mitochondrial cell death protein BNIP3. Oncogene 2005;24:980-991.

15 Kanzawa T, Kondo Y, Ito H, Kondo S, Germano I: Induction of autophagic cell death in malignant glioma cells by arsenic trioxide. Cancer Res 2003;63:2103-2108.

16 Smith DM, Patel S, Raffoul F, Haller E, Mills GB, Nanjundan M: Arsenic trioxide induces a beclin-1independent autophagic pathway via modulation of SnoN/SkiL expression in ovarian carcinoma cells. Cell Death Differ 2010;17:1867-1881.

17 Chiu HW, Lin JH, Chen YA, Ho SY, Wang YJ: Combination treatment with arsenic trioxide and irradiation enhances cell-killing effects in human fibrosarcoma cells in vitro and in vivo through induction of both autophagy and apoptosis. Autophagy 2010;6:353-365.

18 Cohen KJ, Gibbs IC, Fisher PG, Hayashi RJ, Macy ME, Gore L: A phase I trial of arsenic trioxide chemoradiotherapy for infiltrating astrocytomas of childhood. Neuro Oncol 2013;15:783-787.

19 Schmukler E, Wolfson E, Haklai R, Elad-Sfadia G, Kloog Y, Pinkas-Kramarski R: Chloroquine synergizes with FTS to enhance cell growth inhibition and cell death. Oncotarget 2013;5:173-184.

20 Adiseshaiah PP, Clogston JD, McLeland CB, Rodriguez J, Potter TM, Neun BW, Skoczen SL, Shanmugavelandy SS, Kester M, Stern ST, McNeil SE: Synergistic combination therapy with nanoliposomal C6-ceramide and vinblastine is associated with autophagy dysfunction in hepatocarcinoma and colorectal cancer models. Cancer Lett 2013;337:254-265.

21 Kanzawa T, Germano IM, Komata T, Ito H, Kondo Y, Kondo S: Role of autophagy in temozolomide-induced cytotoxicity for malignant glioma cells. Cell Death Differ 2004;11:448-457.

22 Goldberg SB, Supko JG, Neal JW, Muzikansky A, Digumarthy S, Fidias P, Temel JS, Heist RS, Shaw AT, McCarthy PO, Lynch TJ, Sharma S, Settleman JE, Sequist LV: A phase I study of erlotinib and hydroxychloroquine in advanced non-small-cell lung cancer. J Thorac Oncol 2012;7:1602-1608.

23 Lotze MT, Maranchie J, Appleman L: Inhibiting autophagy: a novel approach for the treatment of renal cell carcinoma. Cancer J 2013;19:341-347.

24 Mancias JD, Kimmelman AC: Targeting autophagy addiction in cancer. Oncotarget 2011;2:1302-1306.

25 Rangwala R, Leone R, Chang YC, Fecher LA, Schuchter LM, Kramer A, Tan KS, Heitjan DF, Rodgers G, Gallagher M, Piao S, Troxel AB, Evans TL, DeMichele AM, Nathanson KL, O'Dwyer PJ, Kaiser J, Pontiggia L, Davis LE, Amaravadi RK: Phase I trial of hydroxychloroquine with dose-intense temozolomide in patients with advanced solid tumors and melanoma. Autophagy 2014;10:1369-1379.

26 Rosenfeld MR, Ye X, Supko JG, Desideri S, Grossman SA, Brem S, Mikkelson T, Wang D, Chang YC, Hu J, McAfee Q, Fisher J, Troxel AB, Piao S, Heitjan DF, Tan KS, Pontiggia L, O'Dwyer PJ, Davis LE, Amaravadi RK: A phase I/II trial of hydroxychloroquine in conjunction with radiation therapy and concurrent and adjuvant temozolomide in patients with newly diagnosed glioblastoma multiforme. Autophagy 2014;10:1359-1368.

27 Klionsky DJ, Abdalla FC, Abeliovich H, Abraham RT, Acevedo-Arozena A, Adeli K, et al: Guidelines for the use and interpretation of assays for monitoring autophagy. Autophagy 2012;8:445-544.

28 Gurkar AU, Chu K, Raj L, Bouley R, Lee SH, Kim YB, Dunn SE, Mandinova A, Lee SW: Identification of ROCK1 kinase as a critical regulator of Beclin1-mediated autophagy during metabolic stress. Nat Commun 2013;4:2189.

29 Kimura T, Takabatake Y, Takahashi A, Isaka Y: Chloroquine in cancer therapy: a double-edged sword of autophagy. Cancer Res 2013;73:3-7.

30 Lizaso A, Tan KT, Lee YH: beta-adrenergic receptor-stimulated lipolysis requires the RAB7-mediated autolysosomal lipid degradation. Autophagy 2013;9:1228-1243.

31 Carroll B, Mohd-Naim N, Maximiano F, Frasa MA, McCormack J, Finelli M, Thoresen SB, Perdios L, Daigaku R, Francis RE, Futter C, Dikic I, Braga VM: The TBC/RabGAP Armus coordinates Rac1 and Rab7 functions during autophagy. Dev Cell 2013;25:15-28.

32 Alonso-Curbelo D, Riveiro-Falkenbach E, Perez-Guijarro E, Cifdaloz M, Karras P, Osterloh L, Megias D, Canon E, Calvo TG, Olmeda D, Gomez-Lopez G, Grana O, Sanchez-Arevalo Lobo VJ, Pisano DG, Wang HW, Ortiz-Romero P, Tormo D, Hoek K, Rodriguez-Peralto JL, Joyce JA, Soengas MS: RAB7 controls melanoma progression by exploiting a lineage-specific wiring of the endolysosomal pathway. Cancer Cell 2014;26:6176. 
33 Takeuchi H, Kondo Y, Fujiwara K, Kanzawa T, Aoki H, Mills GB, Kondo S: Synergistic augmentation of rapamycin-induced autophagy in malignant glioma cells by phosphatidylinositol 3-kinase/protein kinase B inhibitors. Cancer Res 2005;65:3336-3346.

34 Codogno P, Meijer AJ: Autophagy and signaling: their role in cell survival and cell death. Cell Death Differ 2005;12 Suppl 2:1509-1518.

35 Marino G, Niso-Santano M, Baehrecke EH, Kroemer G: Self-consumption: the interplay of autophagy and apoptosis. Nat Rev Mol Cell Biol 2014;15:81-94.

36 Booth LA, Tavallai S, Hamed HA, Cruickshanks N, Dent P: The role of cell signalling in the crosstalk between autophagy and apoptosis. Cell Signal 2014;26:549-555.

37 Fan YJ, Zong WX: The cellular decision between apoptosis and autophagy. Chin J Cancer 2013;32:121-129.

38 Ma X, Liu H, Foyil SR, Godar RJ, Weinheimer CJ, Hill JA, Diwan A: Impaired autophagosome clearance contributes to cardiomyocyte death in ischemia/reperfusion injury. Circulation 2012;125:3170-3181.

39 Geng Y, Kohli L, Klocke BJ, Roth KA: Chloroquine-induced autophagic vacuole accumulation and cell death in glioma cells is p53 independent. Neuro Oncol 2010;12:473-481.

40 Szatmari Z, Sass M: The autophagic roles of Rab small GTPases and their upstream regulators: a review. Autophagy 2014;10:1154-1166.

41 Steffan JJ, Dykes SS, Coleman DT, Adams LK, Rogers D, Carroll JL, Williams BJ, Cardelli JA: Supporting a role for the GTPase Rab7 in prostate cancer progression. PLoS One 2014;9:e87882. 